\title{
Respiratory Neurons Mediating the Breuer-Hering Reflex Prolongation of Expiration in Rat
}

\author{
Fumiaki Hayashi, Sharon K. Coles, and Donald R. McCrimmon \\ Department of Physiology, Northwestern University Medical School, Chicago, Illinois 60611-3008
}

\begin{abstract}
Afferent input from pulmonary stretch receptors is important in the control of the timing of inspiratory and expiratory phases of the respiratory cycle. The current study was undertaken to identify neurons within a column of respiratory neurons in the ventrolateral medulla (termed the ventral respiratory group, VRG) that, when activated by lung inflation, produce the Breuer-Hering $(\mathrm{BH})$ reflex in which lung inflation causes inspiratory termination and expiratory prolongation. Intracellular recordings of VRG neurons revealed three groups of inspiratory (I) and two groups of expiratory (E) neurons similar to previous descriptions: I-augmenting (I-Aug), I-decrementing (I-Dec), I-plateau (I-All), E-augmenting (E-Aug), and E-decrementing (E-Dec) neurons. Low-intensity, low-frequency stimulation of a vagus nerve elicited paucisynaptic EPSPs in E-Dec, I-Aug, and I-All neurons that could be divided into two groups on the basis of latency (2.8 $\pm 0.1 \mathrm{msec}, n=10 ; 4.0 \pm 0.1 \mathrm{msec}, n=17)$.
\end{abstract}

IPSPs were elicited in I-Aug and I-All neurons $(4.8 \pm 0.1 \mathrm{msec}$, $n=12)$. However, only E-Dec neurons were depolarized when the $\mathrm{BH}$ reflex was activated by lung inflation $\left(7.5 \mathrm{~cm} \mathrm{H}_{2} \mathrm{O}\right)$ or mimicked by vagus nerve stimulation $(50 \mathrm{~Hz})$. All other neurons were hyperpolarized and ceased firing during $\mathrm{BH}$ reflexmediated expiratory prolongation. A subset of E-Dec neurons (termed $\mathrm{E}-\mathrm{Dec}_{\text {early }}$ ) discharged before inspiratory termination and could contribute to inspiratory termination. The findings are consistent with the hypothesis that a group of E-Dec neurons receives a paucisynaptic (probably disynaptic) input from pulmonary afferents and, in turn, inhibits inspiratory neurons, thereby lengthening expiration.

Key words: Breuer-Hering reflex; control of breathing; pulmonary stretch receptor; respiratory pattern; vagus nerve; ventral respiratory group
Afferent modulation is a critical component of all movements. In locomotion, for example, the detailed coordination between legs depends on afferent input, which determines the precise timing of phase transitions (Rossignol et al., 1988). For breathing movements, pulmonary afferents provide powerful and important modulation of inspiratory and expiratory phase timing as well as respiratory muscle pattern. Lung inflation activates slowly adapting pulmonary stretch receptors, which have axons in the vagus nerve and give rise to the Breuer-Hering $(\mathrm{BH})$ reflex, consisting of inspiratory (I) termination and expiratory (E) prolongation. The first neuron in the reflex pathway is likely to be interneurons, termed pump cells, in the nucleus of the tractus solitarius (Bonham and McCrimmon, 1990). In preliminary work (our unpublished observations), intracellular and extracellular labeling suggests that these neurons send axons toward a column of respiratory neurons in the ventrolateral medulla termed the ventral respiratory group (VRG; Feldman, 1986). In cats, activation of at least two groups of propriobulbar VRG neurons may account for the $\mathrm{BH}$ reflex changes in respiratory pattern (Richter et al., 1986). One group (late-I neurons) discharges briefly at the I-E

Received March 6, 1996; revised July 8, 1996; accepted July 25, 1996.

This work was supported by National Institutes of Health Grant HL-40336. S.K.C. was supported by National Institutes of Health/National Research Service Award HL-08298. We thank Drs. John Miller and Shaun Morrison for helpful comments on this manuscript.

Correspondence should be addressed to Donald R. McCrimmon, Northwestern University Medical School, Department of Physiology M211, 303 East Chicago Avenue, Chicago, IL 60611-3008.

Dr. Hayashi's permanent address: Second Department of Physiology, Chiba University, School of Medicine, Inohana 1-8-1, Chuo-ku, Chiba City, Chiba 260, Japan.

Dr. Coles' permanent address: Department of Medicine, Division of Pulmonary and Critical Care Medicine, University Hospitals, 11100 Euclid Avenue, Cleveland, OH 44106-5067.

Copyright (C) 1996 Society for Neuroscience $0270-6474 / 96 / 166526-11 \$ 05.00 / 0$ phase transition and is excited by lung inflation (Feldman and Cohen, 1978). However, the failure of cross-correlation analysis to reveal a significant inhibitory input from late-I neurons to other I neurons raises questions about the proposed role of these neurons in inspiratory termination (Feldman and Speck, 1983; Segers et al., 1987).

A second group, termed E-Dec (or postinspiratory) neurons, is also excited by lung inflation or vagus nerve stimulation in cats (Feldman and Cohen, 1978; Richter, 1982; Remmers et al., 1986; Manabe and Ezure, 1988) and rats (Parkes et al., 1994). These neurons characteristically begin to discharge immediately after the I-E phase transition and then exhibit a declining rate of discharge, becoming silent before the onset of the next I phase. Lung inflation prolongs the period of activity of these neurons, at least in cats, thereby providing a potential mechanism for prolonging expiration (Feldman and Cohen, 1978; Remmers et al., 1986; Richter et al., 1986; Manabe and Ezure, 1988). Consistent with this hypothesis, E-Dec neurons provide inhibitory input to medullary inspiratory and expiratory neurons in cats (Lindsey et al., 1987; Ezure and Manabe, 1988; Manabe and Ezure, 1988).

The current study examined the hypothesis that activation of E-Dec neurons is responsible for the $\mathrm{BH}$ reflex-mediated prolongation of expiration in rats. An underlying assumption was that the expiratory prolongation occurs by an active process in which a group of inhibitory neurons is paucisynaptically activated by stretch receptors during lung inflation. Hence, two criteria were established for the identification of candidate VRG neurons with a central role in expiratory prolongation. The neurons must (1) be activated during $\mathrm{BH}$ reflex-induced expiratory prolongation and (2) exhibit paucisynaptic EPSPs in response to vagus nerve stim- 

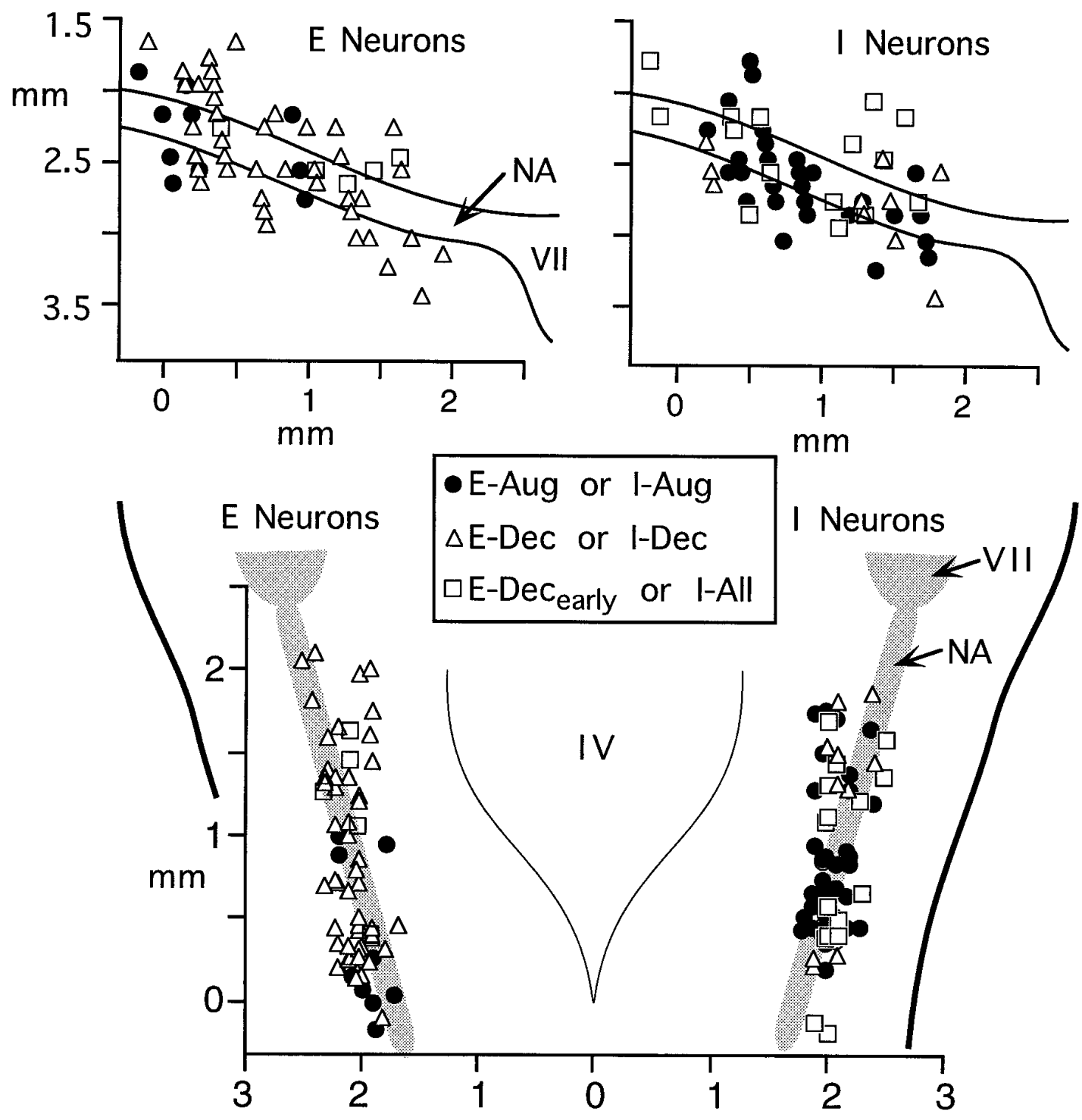

$\mathrm{mm}$

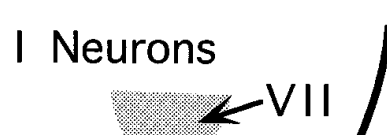




\section{I-Dec E-Dec}
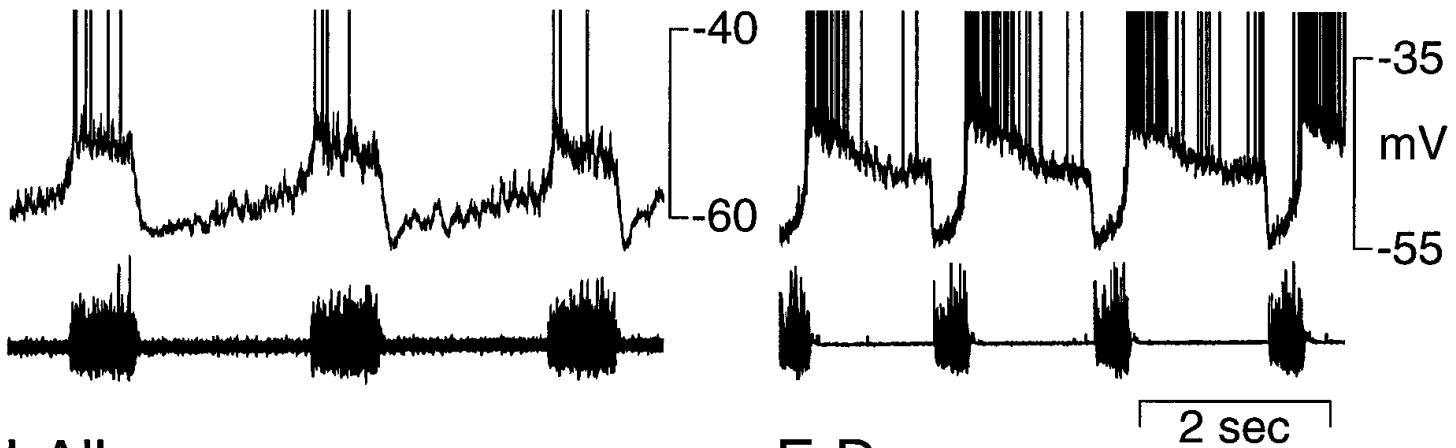

I-All
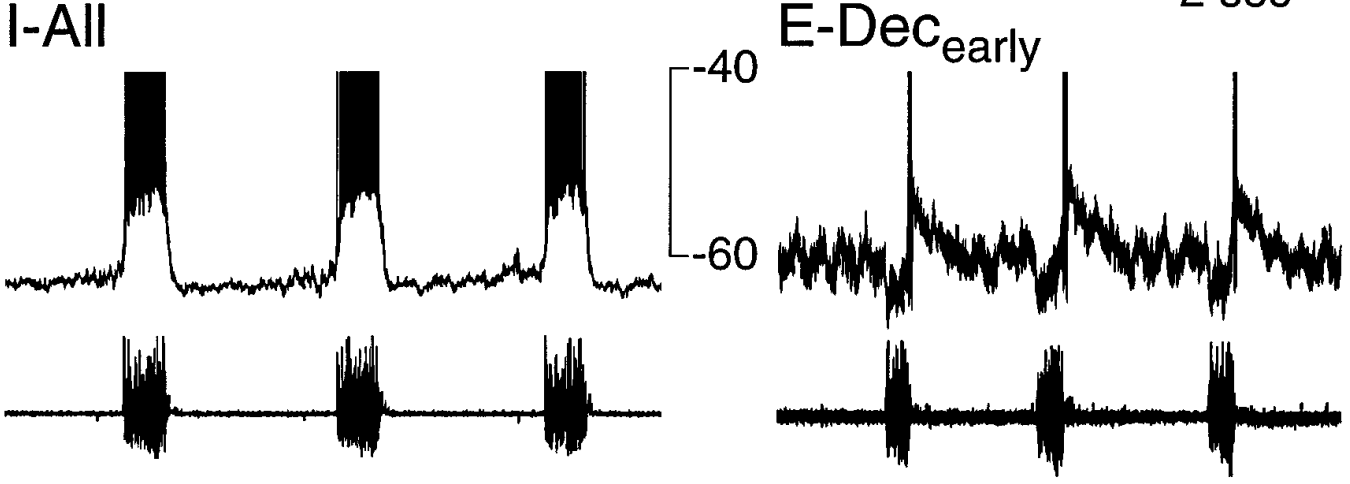

I-Aug
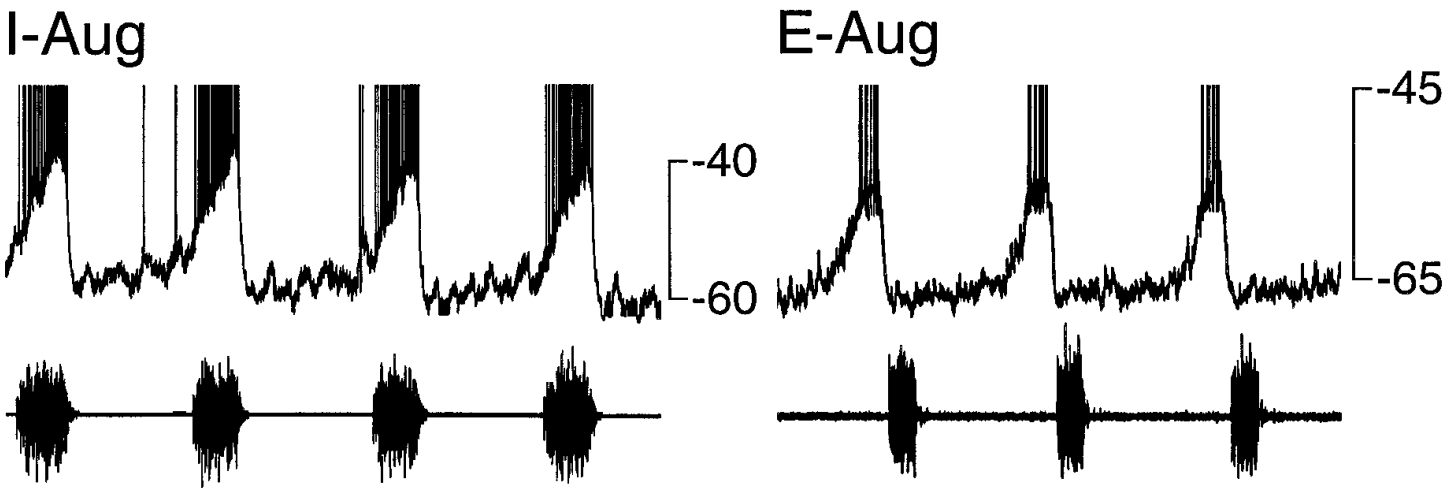

Figure 2. Patterns of respiratory-related membrane potential changes recorded from nonantidromically activated neurons in the ventral respiratory group of the rat. I-Dec, Decrementing inspiratory; I-All, constantly discharging inspiratory; I-Aug, augmenting inspiratory; E-Dec, decrementing expiratory; $E-D e c_{\text {early }}$, early onset expiratory-decrementing; E-Aug, augmenting expiratory. Top trace in each panel is membrane potential (action potentials are clipped); bottom trace is phrenic nerve activity.

process of $\mathrm{T}_{2}$ were fixed by clamps. In three animals bipolar stimulating electrodes were inserted bilaterally into the lateral funiculi of spinal cord segment $\mathrm{C}_{2}$ and positioned at the depth at which maximal orthodromic activation of the phrenic nerve was elicited. Large parietal and occipital craniotomies and a laminectomy $\left(\mathrm{C}_{1}-\mathrm{C}_{4}\right)$ were made to minimize movement artifact. In some animals the caudal part of the cerebellum was removed to facilitate access to the rostral medulla. The pia mater was removed at the point of electrode entry, and the exposed medulla and spinal cord were covered with warmed paraffin oil.

Stimulation and recording. Efferent nerve activity was amplified (bandpass filter, 100-10,000 Hz), rectified, integrated (Paynter filter; time constant, $15 \mathrm{msec}$ ), and recorded on magnetic tape. Glass microelectrodes for intracellular recording were beveled and filled with $2 \mathrm{M}$ $\mathrm{K}$-citrate (DC resistance 8-20 $\mathrm{M} \Omega$ ). The bridge balance of the electrode was monitored by applying a $2-3 \mathrm{~Hz}$ hyperpolarizing current pulse (4 msec, 0.1-0.5 nA). Intracellular membrane potentials (DC) were recorded by using a high-impedance circuit (Axoclamp 2A, Axon Instruments, Foster City, CA). To visualize synaptic noise, we amplified and bandpass-filtered intracellular membrane potentials $(100-10,000 \mathrm{~Hz})$. In some experiments, PSPs evoked by stimulation of a vagus nerve were revealed with the aid of averaging the response to 7-20 stimulus pulses.
Membrane potentials were measured as the difference between intraand extracellular potentials by using a silver, silver chloride reference electrode inserted into a neck muscle. Only neurons with membrane potentials more negative than $-40 \mathrm{mV}$ were included in this study.

Respiratory neurons were recorded within a column of cells corresponding to the VRG in rats (Ezure et al., 1988; Schwarzacher et al., 1991) extending between $1.5 \mathrm{~mm}$ rostral and $0.5 \mathrm{~mm}$ caudal to calamus scriptorius, $1.7-2.5 \mathrm{~mm}$ lateral to the midline, and $1.7-3.5 \mathrm{~mm}$ ventral to the dorsal surface. The electrode was angled rostrally $16^{\circ}$ from vertical and advanced by a piezo stepping motor. In some experiments Neurobiotin (Vector Laboratories, Burlingame, CA) was injected intracellularly for subsequent histological identification of the location of recorded cells ( $4 \%$ in $1 \mathrm{~m} \mathrm{~K}$-citrate; +2 to $+8 \mathrm{nA}, 2 \mathrm{~Hz}, 80 \%$ duty cycle). Antidromic stimulation ( $0.1 \mathrm{msec}$ pulse, $2-3 \mathrm{~Hz}$, up to $1 \mathrm{~mA}$ ) was used to identify cranial motoneurons and bulbospinal neurons according to the criteria described by Lipski (1981).

At the end of an experiment animals were perfused transcardially with heparinized saline, followed by $4 \%$ paraformaldehyde in $0.1 \mathrm{~m}$ PBS or $10 \%$ formalin. The excised brain tissue was transferred to a $20 \%$ sucrosefixative mixture for at least $12 \mathrm{hr}$. Coronal sections, 40-100 $\mu \mathrm{m}$ thick, were cut on a cryostat, and the tissue was processed by the protocol for 
biotin histochemistry described by Kita and Armstrong (1991). Intracellular potentials, tracheal pressure, arterial blood pressure, and synaptic noise were displayed on a chart recorder and stored on magnetic tape.

The $\mathrm{BH}$ reflex was activated (in vagus intact animals) by turning off the ventilator and applying an expiratory pressure of $7.5 \mathrm{~cm} \mathrm{H}_{2} \mathrm{O}(n=29)$ or was mimicked by stimulation of one vagus nerve $(50 \mathrm{~Hz}, 0.1 \mathrm{msec}$ pulse duration; current, $1-3$ times threshold; $n=29$; Feldman and Gautier, 1976). The threshold current for producing the BH reflex was defined as the current that elicited a $3 \mathrm{sec}$ apnea. Both lung inflation and vagus stimulation elicited apneas lasting $\sim 5 \mathrm{sec}$. In some rats, apnea was produced by stimulation $(50 \mathrm{~Hz}, 0.1 \mathrm{msec}$ pulse duration; current, 1-3 times threshold; $n=8$ ) of a superior laryngeal nerve. As with vagus nerve stimulation, the threshold current for superior laryngeal nerve stimulation was defined as the current producing a $3 \mathrm{sec}$ apnea.

\section{RESULTS}

\section{Classification of respiratory neurons}

Stable intracellular recordings were obtained from 175 VRG neurons, 136 of which were not antidromically activated by either cranial nerve (36 experiments) or spinal cord (3 experiments) stimulation. Discharge patterns and phasic modulation of membrane potentials were used to designate subgroups of I and E cells with the nomenclature of Feldman (1986) and Ezure (1990). Figure 1 depicts the distribution (based on recording coordinates relative to the calamus scriptorius) within the VRG of recorded neurons that were not antidromically activated from a cranial nerve or the spinal cord. A predominance of expiratory neurons was recorded in the most rostral aspect in a region known as the Bötzinger complex (Feldman, 1986). Additionally, E-Dec early $_{\text {neu- }}$ rons were localized to regions that correspond to the rostral VRG or pre-Bötzinger complex (Smith et al., 1991a), and E-Aug neurons were localized caudally.

\section{Inspiratory neurons}

Seventy nonantidromically activated neurons (51\% of nonantidromically activated neurons) discharged during I and were divided into three subgroups: I-decrementing (I-Dec), I-continuous (I-All), and I-augmenting (I-Aug). I-Dec neurons ( $n=10,14 \%$ of I neurons) rapidly depolarized to a minimum level early in inspiration (Fig. 2). They then gradually repolarized
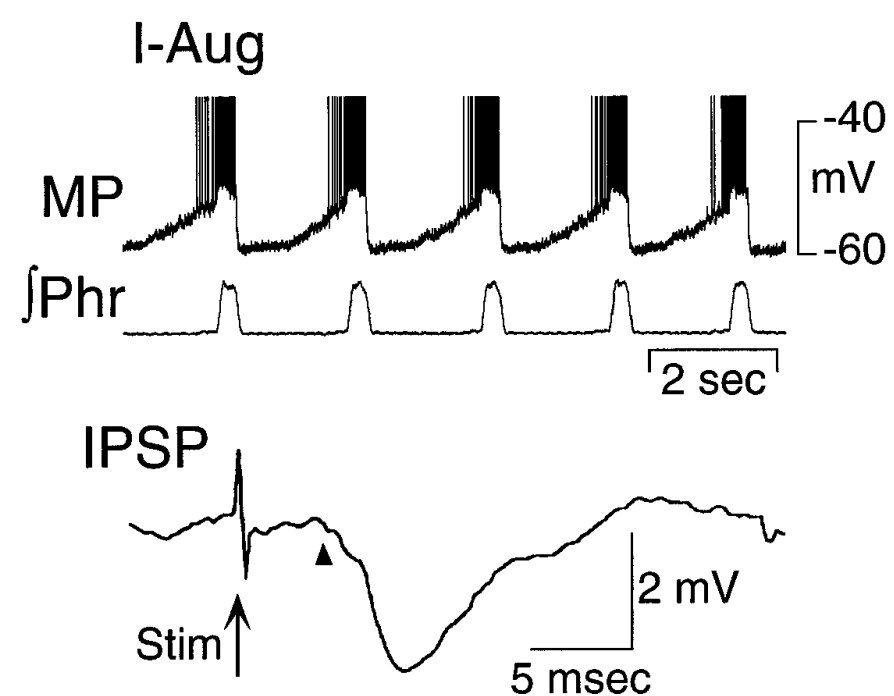

Figure 3. An I-Aug neuron recorded in the rostral VRG. Top panel, The membrane potential $(M P)$ begins to depolarize midway through expiration and reaches maximal depolarization during I. Action potentials are clipped; bottom trace is integrated phrenic nerve activity ( $\left.\int P h r\right)$. Note that depolarization begins midway through expiration in this vagotomized rat. Bottom panel, Averaged IPSP (10 sweeps) evoked in the same neuron by electrical stimulation of the ipsilateral vagus nerve. Arrow indicates stimulus (Stim) artifact. Arrowhead indicates IPSP onset.

and exhibited a declining rate of discharge. I-All neurons $(n=16$, $23 \%$ ) exhibited a bell-shaped or relatively constant level of depolarization throughout I (Figs. 2, 6). I-Aug neurons began a progressive depolarization either at the onset of phrenic nerve activity ( $n=34$, 49\%; Fig. 2), or midway through expiration ( $n=10,14 \%$; stage II expiration; Schwarzacher et al., 1991; Smith et al., 1991b), reaching a minimum potential at the end of I (Fig. 3). Membrane potentials for each of these groups were measured during the silent period of the neuron and are presented in Table 1.

The 10 I-Aug neurons that began depolarizing during expira-

Table 1. Latencies of postsynaptic potentials (PSPs) and membrane potentials observed in nonantidromically activated respiratory (VRG) neurons in adult rats

\begin{tabular}{|c|c|c|c|c|}
\hline Neuron type & EPSPs (latency ${ }^{a}$ msec) & IPSPs (latency msec) & Total tested & $V_{\mathrm{m}}(\mathrm{mV})(n)$ \\
\hline I-Dec & 0 & 0 & 3 & $-53 \pm 3(9 / 10)$ \\
\hline I-All & $\begin{array}{l}2 \\
(\mathrm{SL}=2.6,3.2)\end{array}$ & $\begin{array}{l}2 \\
(4.6,5.0)\end{array}$ & 16 & $-52 \pm 3(13)$ \\
\hline I-Aug & $\begin{array}{l}5 \\
(\mathrm{SL}=2.7 \pm 0.1 ; n=4) \\
(\mathrm{LL}=4.4)\end{array}$ & $\begin{array}{l}10 \\
(4.8 \pm 0.1)\end{array}$ & 23 & $-55 \pm 8(29)$ \\
\hline E-Dec $_{\text {early }}$ & $\begin{array}{l}2 \\
(3.8,4.0)\end{array}$ & 0 & 3 & $-62 \pm 4(5)$ \\
\hline E-Aug & 0 & 0 & 8 & $-59 \pm 5(8)$ \\
\hline
\end{tabular}

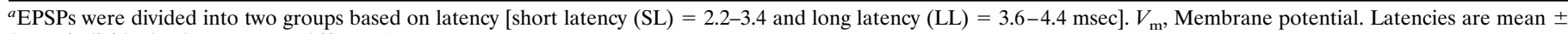
SEM; individual values presented if $n<3$. 


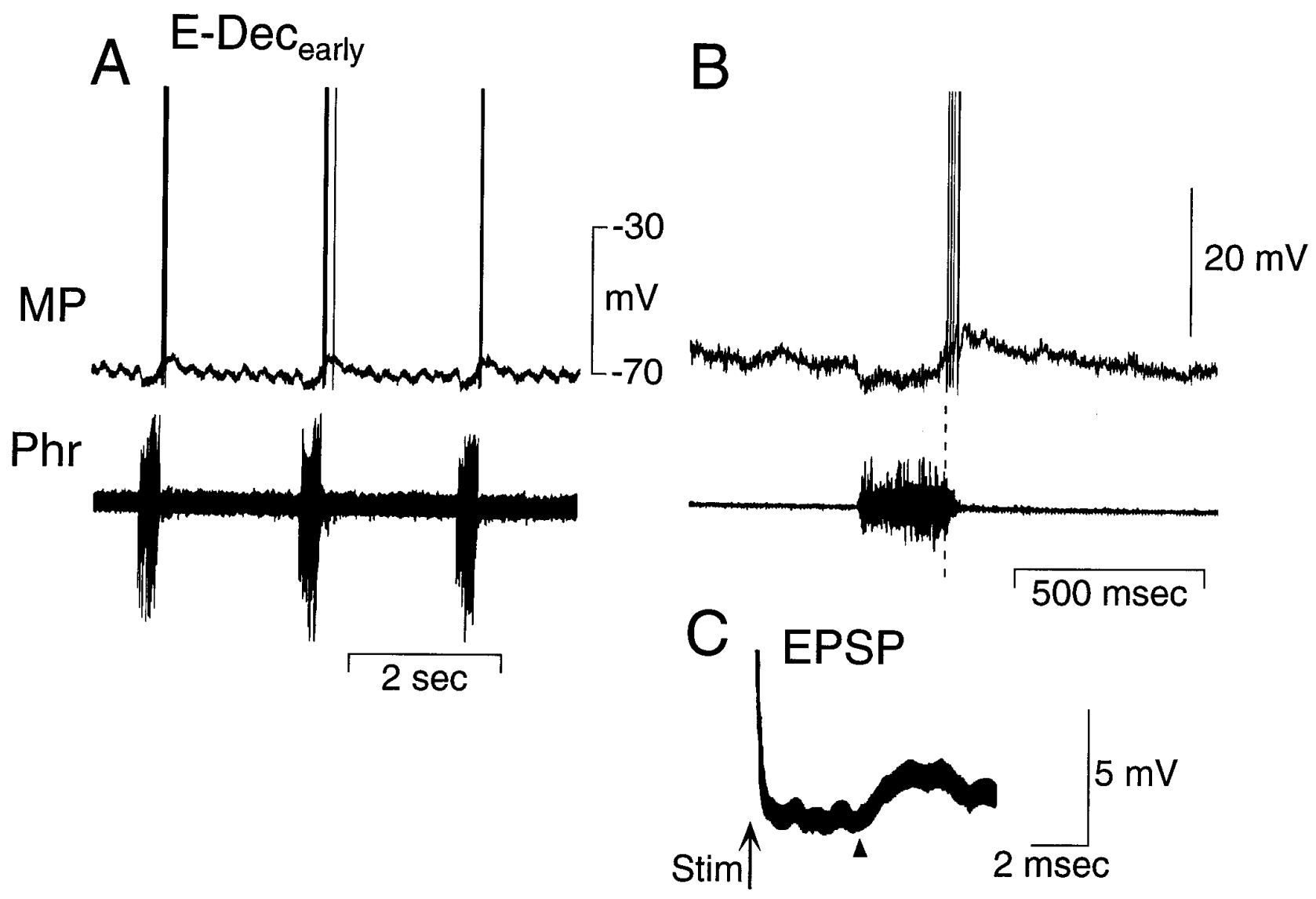

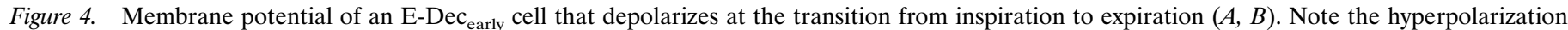
of the E-Dec $c_{\text {early }}$ cell during most of the phrenic nerve burst. The dashed line in $B$ correlates the first spike in the E-Dec early cell with the ongoing phrenic nerve activity. $C$, Short latency EPSP evoked in the same neuron by stimulation (at arrow) of the ipsilateral vagus nerve. Arrow indicates stimulus (Stim) artifact. Arrowhead indicates EPSP onset. MP, Membrane potential; Phr, phrenic nerve activity.

tion were recorded in vagotomized rats. A similar group of E-I phase-spanning neurons has been reported by Schwarzacher et al. (1991) and Smith et al. (1991b). We pooled the E-I neurons with the I-Aug neurons for the following reasons. No E-I phasespanning neurons were recorded in 19 vagus intact animals, which suggested that vagal input suppressed the E-phase activity. As noted by Schwarzacher et al. (1991), passage of a weak hyperpolarizing current readily abolished the expiratory phase depolarization of these neurons, thereby revealing a typical I-Aug pattern of discharge. In addition, the responses to lung inflation and repetitive stimulation of the vagus nerve and the pattern of PSPs to single-pulse vagus nerve stimulation seen in these neurons closely resembled those in I-Aug neurons.

\section{Expiratory neurons}

Sixty-six nonantidromically activated neurons (49\%) depolarized during $\mathrm{E}$ and were divided into two subgroups: E-decrementing (E-Dec) and E-Augmenting (E-Aug) neurons. The largest group, E-Dec neurons ( $n=56,85 \%$ of E neurons), abruptly depolarized near the onset of expiration, followed by a gradual repolarization and decrementing discharge pattern as expiration progressed (Figs. 2, 5, 7, 10). Most of these neurons depolarized immediately after the I-E transition, but a subset of five neurons (termed

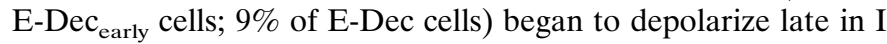
and discharged during the transition from I to E (Figs. 2, 4). These five neurons have the same pattern of membrane potential shifts during the respiratory cycle as E-Dec neurons and thus may represent an extreme pattern of activity in a population of E-Dec neurons with a distribution in times of discharge onset. We have separated them from other E-Dec neurons, because their onset of discharge in late inspiration makes them candidates for participation in the I to E phase transition (Lindsey et al., 1987; Ezure, 1990). E-Aug neurons ( $n=10,15 \%$ of E neurons) depolarized progressively and increased their discharge rate as expiration progressed (Figs. 2, 8). Membrane potentials for each of these groups were measured during the silent period of the neuron and are presented in Table 1.

\section{Cranial motoneurons and bulbospinal neurons}

A total of 36 motoneurons were activated antidromically by stimulation of cranial nerves. Of these, 28 (E-Dec, 17; I-Aug, 10; I-All, 1) were antidromically activated from the ipsilateral cervical vagus nerve (latency, $1.2 \pm 0.3 \mathrm{msec}$ ), 7 (latency, $0.9 \pm 0.2 \mathrm{msec}$ ) from the pharyngeal branch of the vagus nerve, and 1 (I-Aug) from the superior laryngeal nerve (latency, $1.2 \mathrm{msec}$ ). Two I-Aug neurons

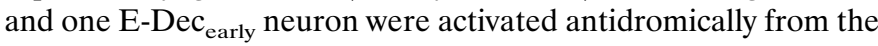
spinal cord (latencies: 1.2, 1.3, $1.5 \mathrm{msec}$ ).

\section{Postsynaptic potentials in response to low-frequency stimulation of the vagus nerve}

Low-frequency stimulation of the ipsilateral vagus nerve elicited PSPs in all classes of nonantidromically activated neurons except I-Dec $(n=3)$ and E-Aug $(n=8$; Table 1$)$. IPSPs had a relatively consistent latency (range, $4.4-5.0 \mathrm{msec}$ ) and were evident chiefly 

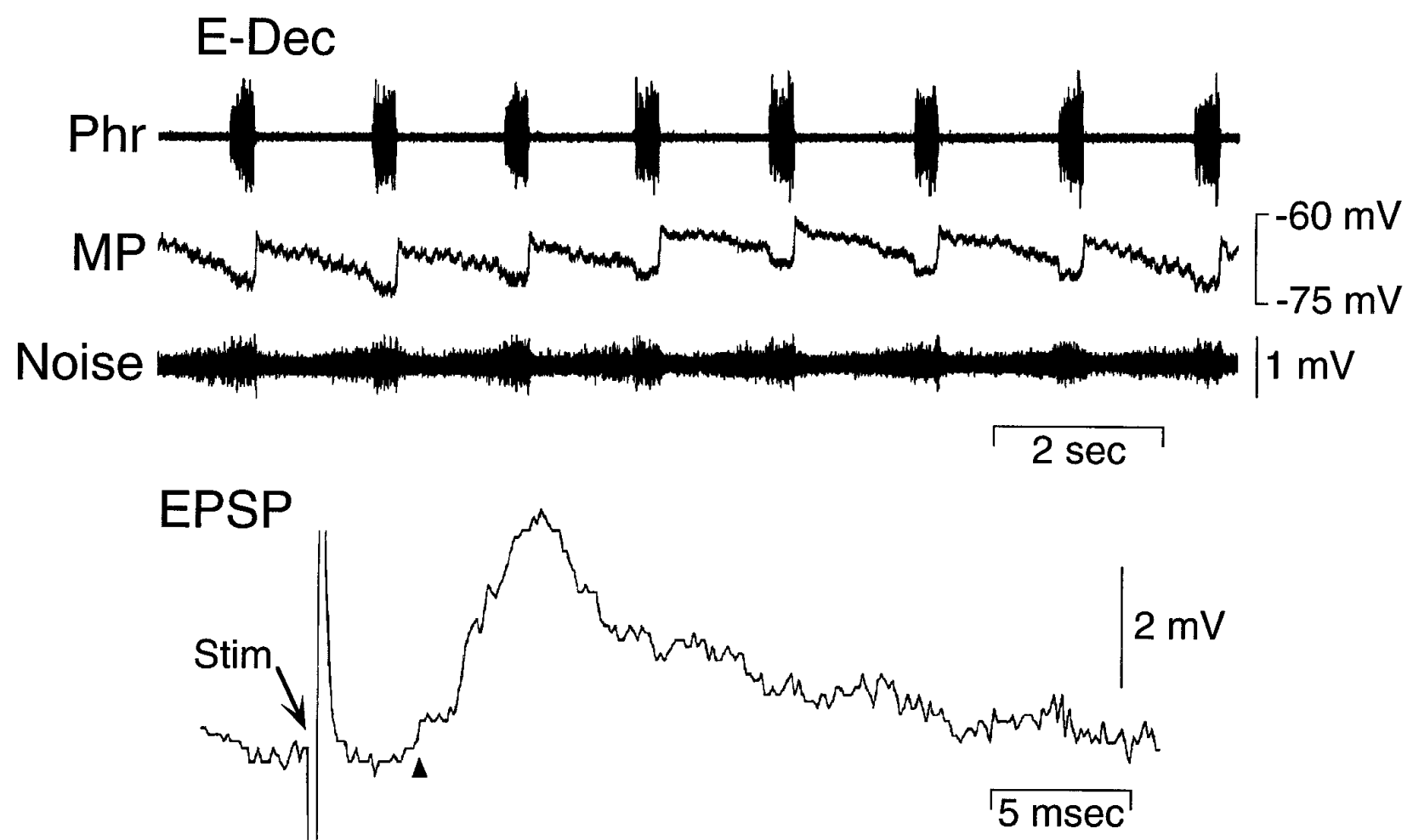

Figure 5. Membrane potential and synaptic input to an E-Dec neuron recorded in the VRG. Bottom panel, EPSP evoked in the same E-Dec neuron by electrical stimulation of the ipsilateral vagus nerve. Arrow indicates stimulus (Stim) artifact. Arrowhead indicates EPSP onset. Phr, Phrenic nerve; $M P$, membrane potential; Noise, amplified and filtered (100-10,000 Hz) MP signal.

in I-Aug neurons (Fig. 3) but also in some I-All neurons (Table 1). EPSPs were divided into two groups on the basis of their latencies. Short latency EPSPs (range, 2.2-3.4 msec; $n=10$ ) were observed in four E-Dec, four I-Aug, and two I-All neurons. Longer latency EPSPs (range, 3.6-4.4 msec; $n=19$ ) were recorded mainly in

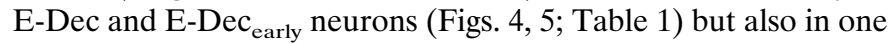
I-Aug neuron. Short and longer latency EPSPs were not observed in the same neuron. Stimulation of the contralateral vagus nerve did not elicit detectable PSPs $(n=15)$. In addition, PSPs were not evident in antidromically identified cranial motoneurons $(n=17)$.

\section{Effects of high-frequency vagus nerve stimulation on membrane potential and discharge patterns of respiratory neurons}

Vagal stimulation was performed at two intensities: (1) at the threshold for producing a prolongation of $E$ and (2) approximately three times this threshold. The latter protocol elicited a cessation of phrenic nerve discharge (neural apnea) lasting several seconds.

\section{Inspiratory neurons}

Stimulation of a vagus nerve at an intensity just above threshold for prolonging expiration reduced the amplitude of the inspiratory-related depolarization of I neurons (Fig. 6, top). At higher stimulus intensities, phrenic nerve activity was abolished, and there was a corresponding lack of phasic depolarization of all I neurons (Fig. 6, bottom).

\section{Expiratory neurons}

The responses of E-Dec and E-Aug neurons to stimulation of the vagus nerve were qualitatively different. In extracellular recordings the activity of E-Dec neurons was prolonged by vagal stim- ulation, whereas that of E-Aug neurons was readily abolished (data not shown). Intracellular recordings revealed stimulus intensity-dependent changes in the membrane potential and firing frequency in both populations of neurons. In E-Dec neurons, stimulus intensities that modestly increased the duration of expiration elicited an increase in discharge frequency and a slight prolongation in the period of membrane depolarization (Fig. 7, top). Increasing the stimulus intensity (to 3 times threshold), caused the depolarization to be maintained throughout the several seconds of vagus nerve stimulation (Fig. 7, bottom). Two of five $\mathrm{E}-\mathrm{Dec}_{\text {early }}$ neurons were tested for their response to vagus nerve stimulation. One depolarized and discharged tonically during stimulation of the vagus, but the second hyperpolarized. All E-Aug neurons ceased discharging during vagal stimulation. In many of these neurons, even low-intensity stimulation that had minimal effect on phrenic nerve activity reduced or abolished the phasic changes in membrane potential (Fig. 8). However, during prolonged low-intensity vagal stimulation, phasic subthreshold alterations in membrane potential gradually reappeared (Fig. 8).

\section{Effects of lung inflation on membrane trajectory and discharge patterns of respiratory neurons}

The effect of lung inflation to $\sim 7.5 \mathrm{~cm} \mathrm{H}_{2} \mathrm{O}$ was determined in 33 neurons. Respiratory-related phasic depolarizations in membrane potentials of I (I-All, $n=1$; I-Aug, $n=14$ ) and E-Aug neurons $(n=1)$ were reduced or abolished during lung inflation (Fig. 9). E-Dec neurons exhibited two qualitatively different responses to lung inflation. In 13 of $17 \mathrm{E}-\mathrm{Dec}$ neurons, the response to lung inflation resembled that to vagus nerve stimulation, consisting of depolarization and a prolonged discharge (Fig. 10A,B). The re- 


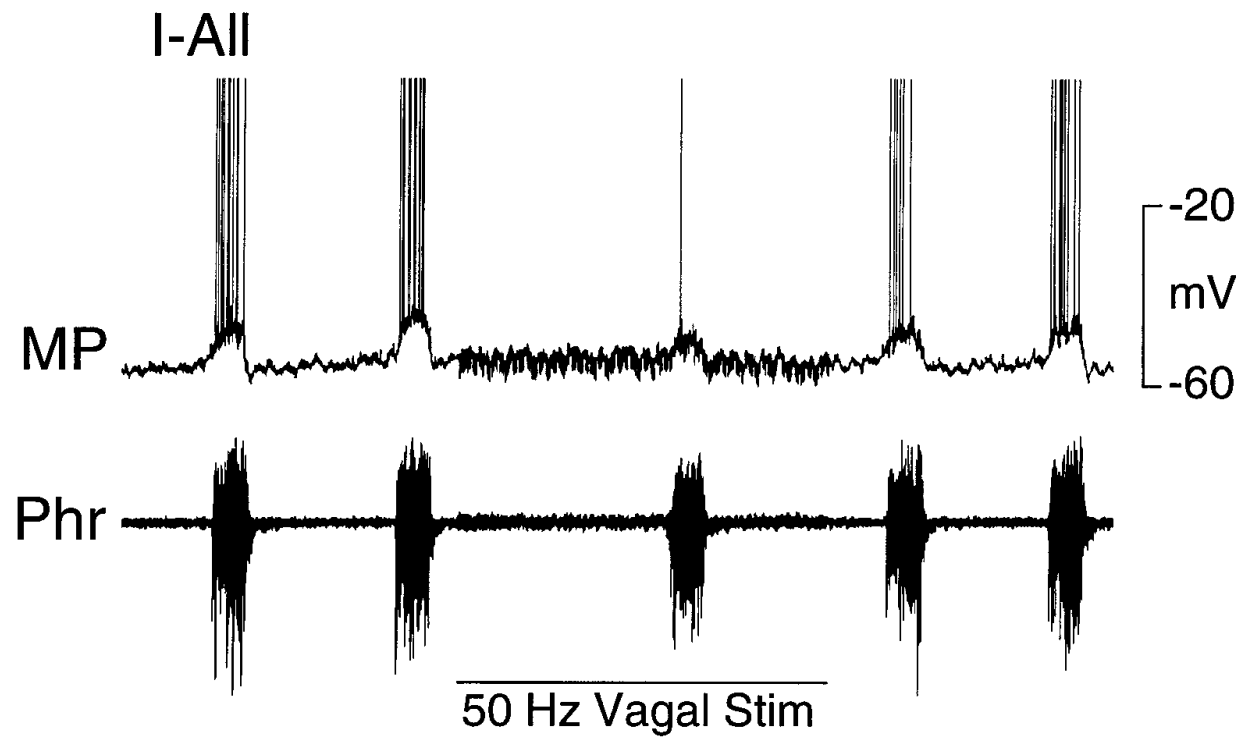

Figure 6. Inhibition of an I-All (top panel) and an I-Aug (bottom panel) neuron by stimulation $(50 \mathrm{~Hz}, 3 \times$ threshold $)$ of the ipsilateral vagus nerve. $M P$, Membrane potential; $P h r$, phrenic nerve activity.

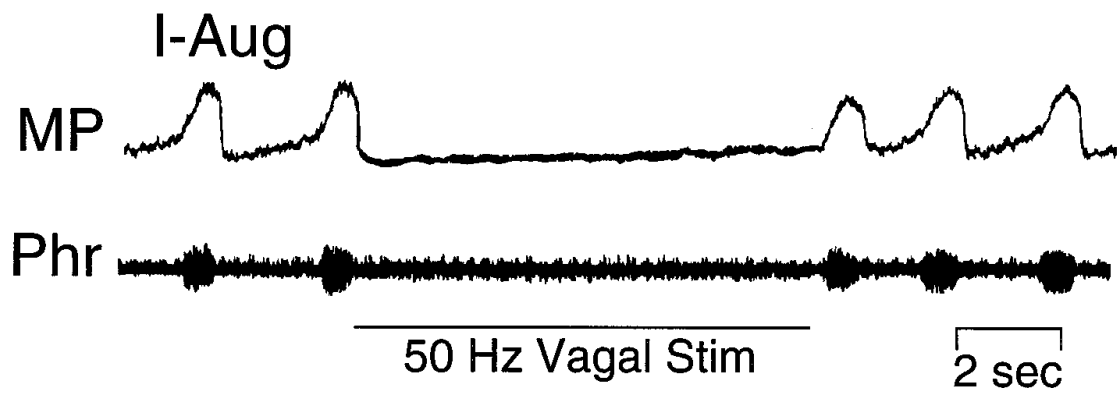

E-Dec
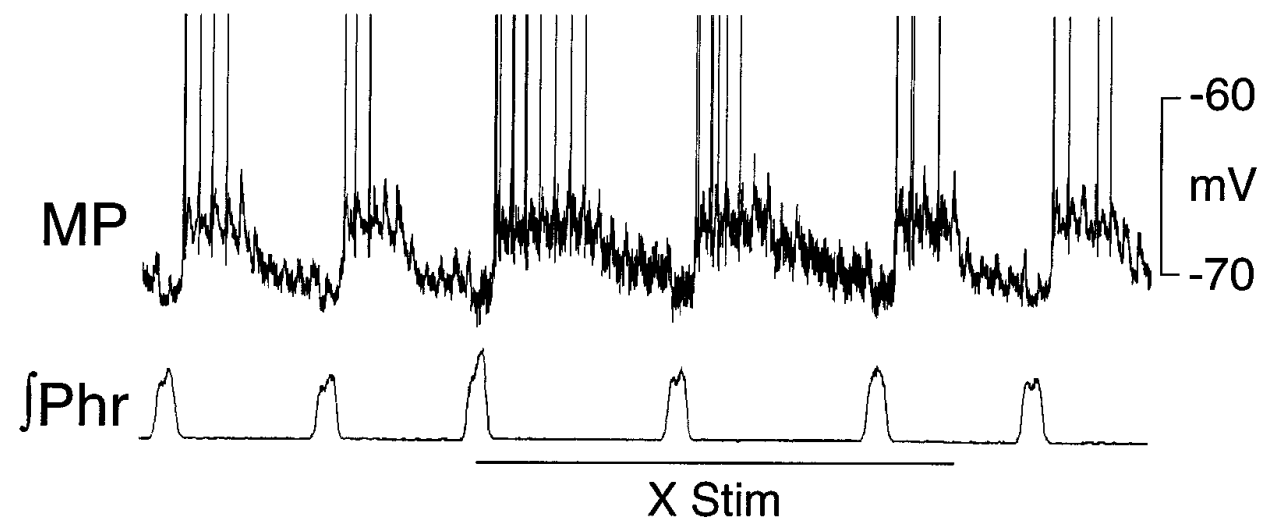

Figure 7. Prolonged depolarization of a E-Dec neuron during stimulation of the ipsilateral vagus nerve at two different intensities. Top panel, A stimulus intensity just above threshold $(50 \mathrm{~Hz}, 1.5 \times$ threshold; $X$ Stim) for producing a prolongation of expiration. Bottom panel, The vagus nerve is stimulated at an intensity $(50 \mathrm{~Hz}, 3 \times$ threshold $)$ sufficient to produce a period of apnea for several seconds. $M P$, Membrane potential; $\int P h r$, integrated phrenic nerve activity; $P h r$, phrenic nerve activity.

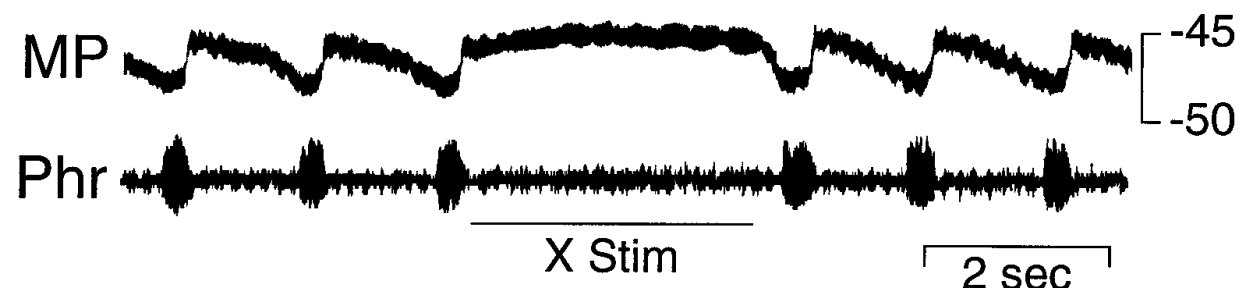

maining four E-Dec neurons were hyperpolarized during lung inflation.

Figure 10 shows a comparison of the effects on one E-Dec neuron of lung inflation and vagus and superior laryngeal nerve stimulation. During maintained lung inflation (Fig. 10A), E periods were prolonged, the rate of E-phase repolarization of the E-Dec neuron slowed, and its period of discharge was prolonged. Both vagus and superior laryngeal nerve stimulation similarly 


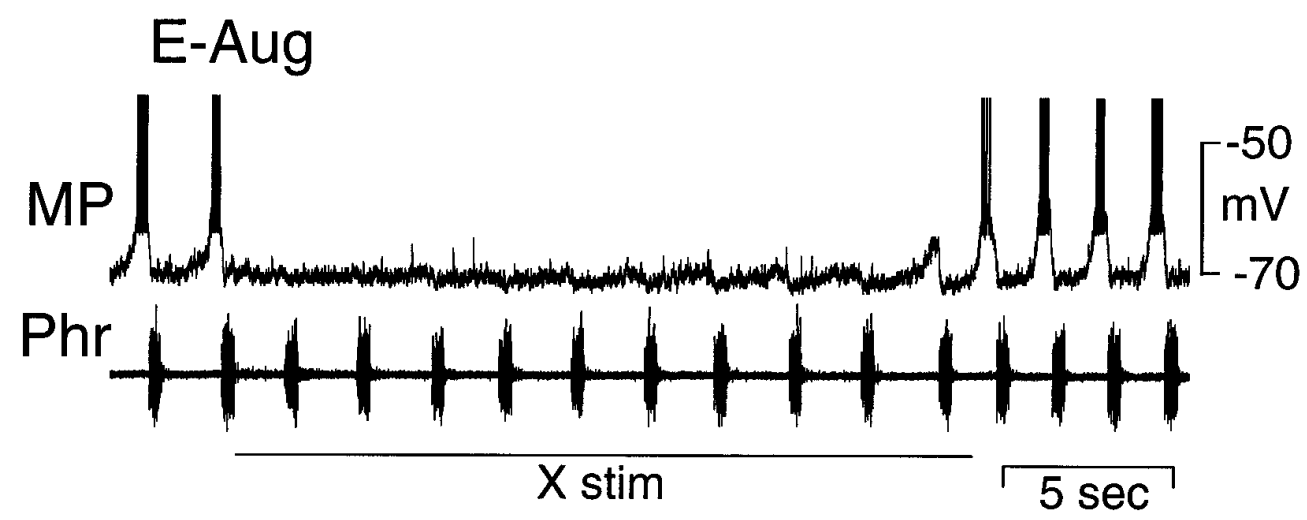

Figure 8. Inhibition of an E-Aug neuron by stimulation $(50 \mathrm{~Hz}, 0.8 \times$ threshold; $X$ stim) of the ipsilateral vagus nerve at an intensity that had little effect on phrenic nerve activity. Note progressive resumption of subthreshold modulation of membrane potential $(M P)$ during continued stimulation. $P h r$, Phrenic nerve activity. prolonged the E period, depolarized the neuron, and even more markedly slowed its E-phase repolarization (Fig. 10B,C). In addition, in the case of superior laryngeal nerve stimulation, when the prolongation of expiration exceeded the period of nerve stimulation (Fig. 10C), the E-Dec neuron remained depolarized, slowly repolarizing until the next I phase. The sensitivity of the E-Dec neuron to volume-related afferent input from the lung is indicated by the depolarizing waves in the membrane potential traces (Fig. 10B,C) that correlate with the ventilator-induced increases in tracheal pressure.

\section{DISCUSSION}

The findings are consistent with activation of a group of propriobulbar E-Dec neurons having a key role in the $\mathrm{BH}$ reflex prolongation of expiration. Low-frequency vagal stimulation induced a short-latency EPSP in these neurons. Although EPSPs were also evoked in several other groups of respiratory neurons, E-Dec neurons were unique in that lung inflation and repetitive stimulation of a vagus nerve caused prolonged depolarization and increased discharge only in this group of neurons.

\section{Firing patterns of respiratory neurons}

The identified subgroups of respiratory neurons were similar to those described in previous reports for the rat and included three groups of I (I-Aug, I-Dec, and I-All) and two groups of E
(E-Dec and E-Aug) neurons (Ezure et al., 1988; Schwarzacher et al., 1991; Smith et al., 1991b; Zheng et al., 1991a,b). An additional group of neurons exhibiting a relatively constant discharge rate throughout E (E-Con neurons; Zheng et al., 1991a,b; Ezure et al., 1988) has been described but was not observed in the present study.

As previously reported for the rat, E-Dec neurons formed the largest group of E neurons (Ezure et al., 1988; Schwarzacher et al., 1991; Zheng et al., 1991a,b). It is likely that some of the E-Dec neurons were cranial motoneurons but were not antidromically activated, because only one or two cranial nerves were stimulated in each experiment. Zheng et al. (1991b) found that 10 of the 11 E-Dec neurons that they labeled with intracellular HRP were located proximal to the nucleus ambiguus and had axonal trajectories indicating they were cranial motoneurons. In the current study, most E-Dec neurons were depolarized by lung inflation, which suggests that many of these cells may not be cranial motoneurons, because lung inflation inhibits the expiratory activity on cranial motoneurons, including those with axons in the pharyngeal branch of the vagus nerve (Hayashi and McCrimmon, 1996). This is consistent with previous reports of inhibition of laryngeal motoneurons during lung inflation in both cats and rats (Barillot and Bianchi, 1971; Bianchi and Barillot, 1975; Fukuda and Honda, 1982).

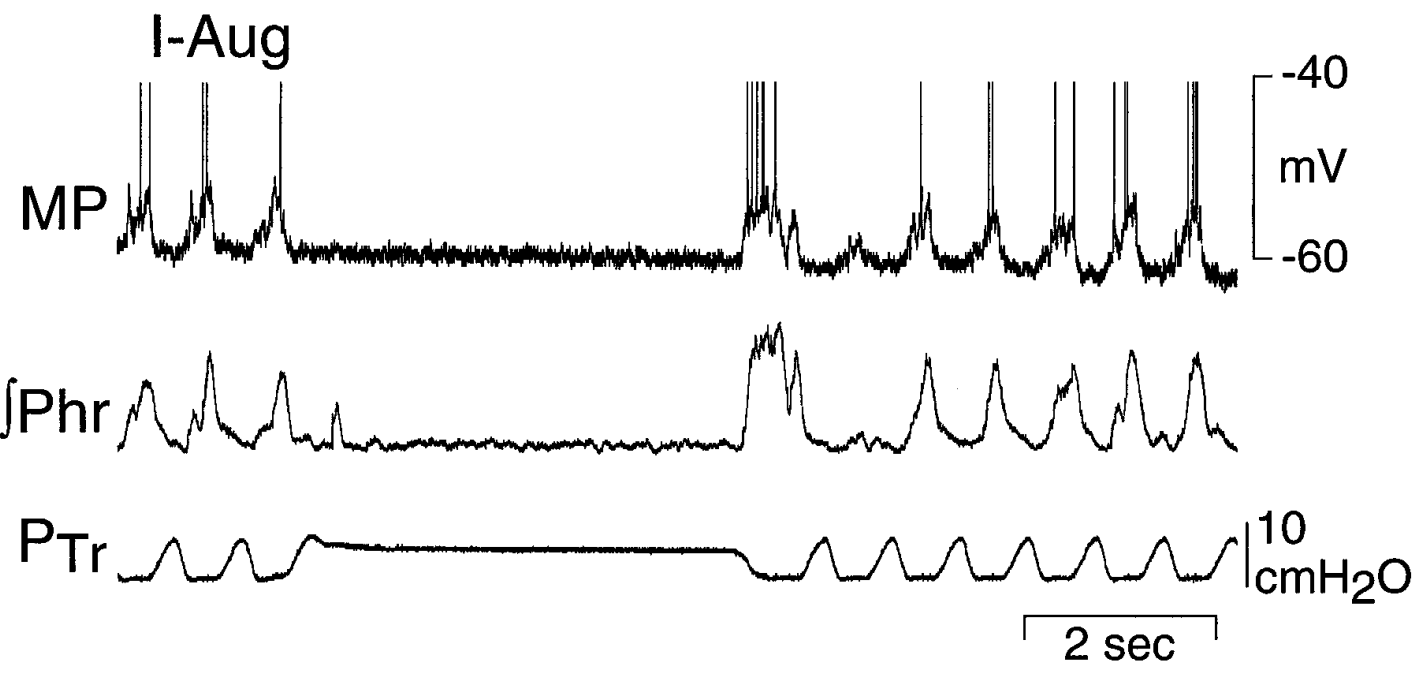

Figure 9. Inhibition of an I-Aug neuron and phrenic nerve activity during lung inflation in a rat with intact vagus nerves. Tracheal pressure was maintained by turning the ventilator off near end expiration. Irregular pattern of phrenic nerve activity during phasic lung inflation is attributable to vagal afferent feedback. $M P$, Membrane potential; $\int P h r$, integrated phrenic nerve activity; $P_{\mathrm{Tr}}$, tracheal pressure. 

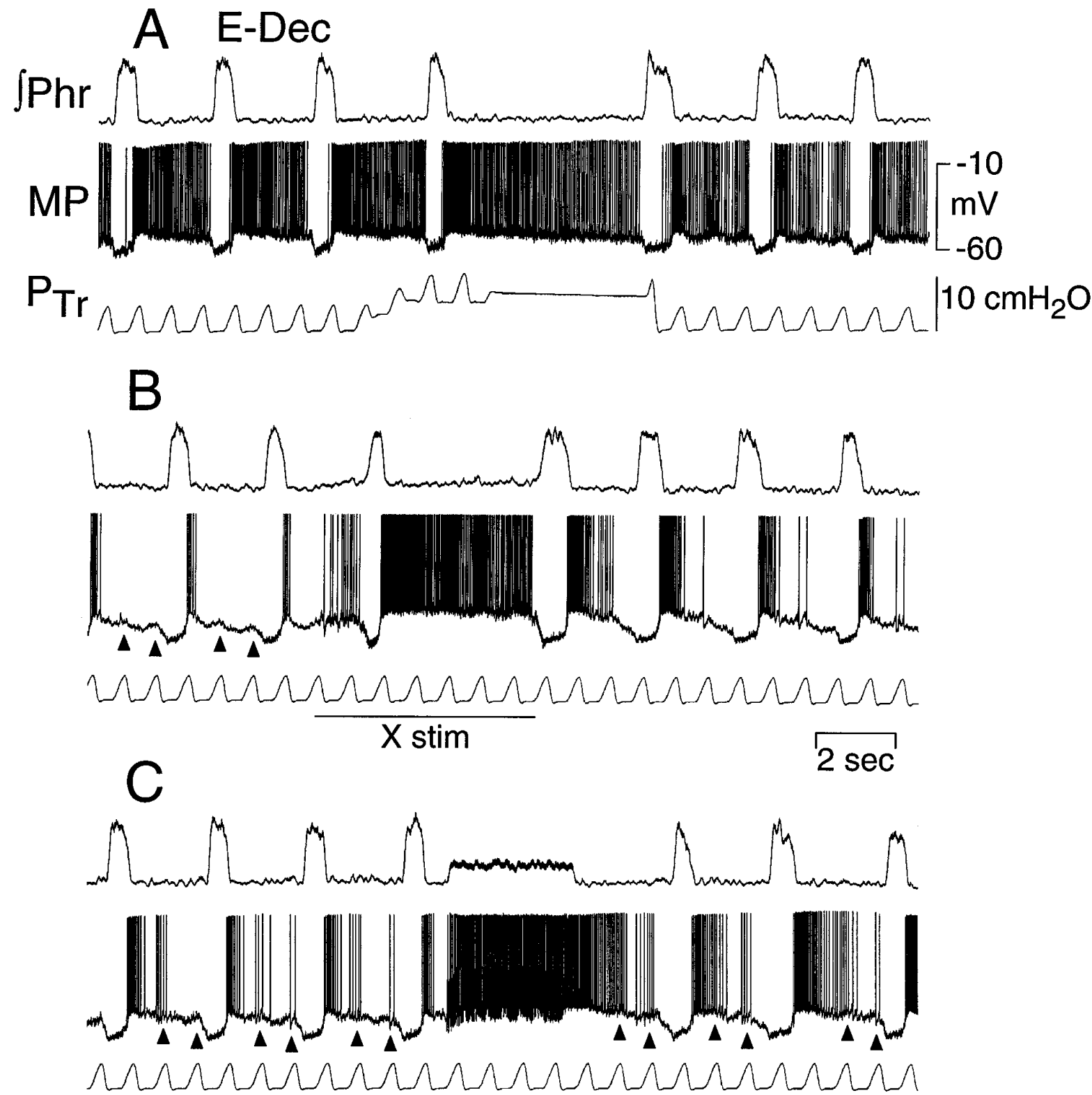

\section{SLN stim}

Figure 10. Activation of an E-Dec neuron by maintained lung inflation and vagus and superior laryngeal nerve stimulation $(50 \mathrm{~Hz}, 3 \times$ threshold $)$ in a rat with intact vagus nerves. $A$, Lung inflation (increased $P_{\mathrm{Tr}}$ ) prolongs expiratory period and increases E-Dec neuron discharge. $B$, Vagus nerve stimulation $(X$ stim; $50 \mu \mathrm{A}, 50 \mathrm{~Hz})$ prolongs expiration and increases E-Dec neural discharge similar to lung inflation. $C$, Superior laryngeal nerve stimulation $(S L N$ stim; $20 \mu \mathrm{A}, 50 \mathrm{~Hz})$ prolongs expiration beyond the period of stimulation and causes a corresponding maintained depolarization of the E-Dec neuron. Arrowheads in $B$ and $C$ indicate depolarization of the E-Dec neuron in phase with the ventilator-induced lung inflation. All traces are from the same neuron. $M P$, Membrane potential; $\int P h r$, integrated phrenic nerve activity; $P_{\mathrm{Tr}}$, tracheal pressure.

\section{Postsynaptic potentials and the response to activation of vagal afferents}

Stimulation of a vagus nerve elicited PSPs in all groups of VRG neurons except I-Dec (3 neurons tested) and E-Aug neurons (8 neurons tested). In contrast, Parkes et al. (1994) found EPSPs in three E-Aug neurons. This difference may be the result of a sampling bias, because relatively few were tested in the present study. Alternatively, it may be a function of the stimulus intensity used. The stimulus intensity in relation to the threshold for evoking expiratory lengthening was not described by Parkes et al. (1994). If they used a higher intensity, smaller diameter afferent fibers may have been activated that could contribute the PSPs in E-Aug neurons.

EPSPs in the remaining groups readily could be divided into two groups on the basis of their latency $(2.8 \pm 0.1$ and $4.0 \pm 0.1$ $\mathrm{msec})$. The shorter latency was comparable to that of $2.78 \pm 0.17$ msec in five E-Dec cells reported by Zheng et al. (1991b) and within the range of $<2-64 \mathrm{msec}$ reported by Parkes et al. (1994) in the rat. Calculation of the expected synaptic latency on the basis of a disynaptic pathway with (1) a primary afferent fiber length of $30 \mathrm{~mm}$ and a conduction velocity of $25 \mathrm{~m} / \mathrm{sec}$ (Averill et al., 1984; Berger and Dick, 1987), (2) second order neurons (presumably 
pump cells; Berger, 1977; Bonham and McCrimmon, 1990) with 3-mm-long axons conducting at $3 \mathrm{~m} / \mathrm{sec}$ (Davies et al., 1987), and (3) two synaptic delays of $0.5 \mathrm{msec}$ each (Jiang and Lipski, 1990) would give a total latency of $3.2 \mathrm{msec}$. Thus, at least the shorter latency EPSPs are likely to derive from a pathway having no more than two synapses.

The presence of EPSPs in E-Dec neurons during low-frequency vagal stimulation is consistent with the observed depolarization of these neurons during lung inflation or electrical stimulation of a vagus nerve. It is also consistent with a role for $\mathrm{E}-\mathrm{Dec}_{\text {early }}$ neurons in the termination of inspiration (Feldman and Cohen, 1978; Richter et al., 1986, 1992; Lindsey et al., 1987; Ezure, 1990). E-Dec $c_{\text {early }}$ cells were the only recorded cells that discharged early enough to account for the inspiratory-to-expiratory phase transition. These cells may be similar to a recent description of burst inspiratory-expiratory (bIE) neurons in cats (Oku et al., 1992) that fire a brief burst of action potentials coincident with the I to E phase transition.

The prolongation of the E phase and coincident depolarization of many E-Dec neurons during lung inflation (even during ventilator-mediated tidal volumes, Fig. 10) as well as during stimulation of a vagus or superior laryngeal nerve is generally consistent with the proposed role of these neurons in the control of expiratory duration (Feldman and Cohen, 1978; Richter et al., 1986, 1992; Lindsey et al., 1989; Ezure, 1990; Ogilvie et al., 1992; Balis et al., 1994; Duffin et al., 1995). Richter et al. (1986) modeled the respiratory cycle as consisting of three phases, with expiration divided into an early (post-I) and a late phase. In their model, a group of E-Dec neurons is identified (post-I cells) that discharge only during the early E phase. They propose that post-I neurons receive pulmonary afferent input and have the central role in determining E duration. In the present study, the discharge pattern of many of the E-Dec neurons excited by lung inflation was not restricted to the post-I period, but these data do not allow us to rule out a central role of post-I neurons in defining expiratory duration. With respect to inspiratory termination, the finding that some E-Dec neurons are excited by pulmonary afferents and begin to discharge before inspiratory termination is consistent with proposals that E-Dec neurons contribute to inspiratory termination (Feldman and Cohen, 1978; Lindsey et al., 1989; Ezure, 1990). However, other models (Richter et al., 1986, 1992) have proposed that late-I neurons play a key role in the I-E phase transition. Because no late-I neurons were recorded in this study, their contribution cannot be ruled out. That some E-Dec neurons are inhibited by lung inflation is consistent with the observation that $\mathrm{E}$ activity on cranial nerves is inhibited by lung inflation (i.e., superior laryngeal nerve and pharyngeal branch of the vagus nerve; Hayashi and McCrimmon, 1996).

Activation of the $\mathrm{BH}$ reflex produces a bilaterally symmetrical inhibition of phrenic nerve activity (Parkes et al., 1994; Hayashi and McCrimmon, 1996). This implies that pulmonary stretch receptor activation has a bilaterally equivalent effect on the discharge of VRG neurons despite the observation that vagus nerve stimulation produced EPSPs only in E-Dec neurons ipsilateral to the stimulated nerve. That this coordination does not require connections between second order neurons (probably pump cells) in the nucleus tractus solitarius is suggested by preliminary studies in which interruption of pathways connecting the left and right nucleus tractus solitarii did not interrupt the $\mathrm{BH}$ reflex (Davies et al., 1987). Alternatively, E-Dec neurons may provide the coordination. These cells have extensive inhibitory connections with neurons in the contralateral VRG in cats (Ezure and Manabe,
1988; Manabe and Ezure, 1988); thus, unilateral activation of these neurons could cause bilateral changes in phrenic nerve discharge.

The functional role of EPSPs in I neurons is less clear, but excitation of VRG I neurons may contribute to a short latency excitation of phrenic nerve that occurs during low-intensity vagus nerve stimulation in rats (Hayashi and McCrimmon, 1996). In addition, electrical stimulation of the vagus nerve is likely to activate afferent pathways other than slowly adapting pulmonary stretch receptors, including rapidly adapting receptor afferents. Activation of the latter afferents can increase inspiratory efforts, at least in other species (Pack, 1981).

IPSPs were observed only in two groups of I neurons (I-Aug and I-All) and were most common in I-Aug neurons. The latency averaged $4.8 \mathrm{msec}$ and was significantly longer (by an average of $0.8 \mathrm{msec}$ ) than the mean of the longest latency EPSPs. This is consistent with the possibility that E-Dec neurons in which EPSPs were observed have inhibitory projections to these I neurons. It is also consistent with the proposed role of these neurons in the control of I and E durations (Feldman and Cohen, 1978; Richter et al., 1986, 1992; Lindsey et al., 1989; Ezure, 1990; Duffin et al., 1995).

In summary, the current findings suggest that E-Dec neurons are uniquely and paucisynaptically activated during the $\mathrm{BH}$ reflex expiratory prolongation. These findings can be combined with those of previous studies to propose a working model of the basic circuitry producing the Breuer-Hering reflex prolongation of expiration. Slowly adapting pulmonary stretch receptor fibers in the vagus nerve monosynaptically activate a group of second order neurons (termed pump cells) in the nucleus of the tractus solitarius (Berger and Dick, 1987; Bonham and McCrimmon, 1990; Bonham et al., 1993). Pump cells then activate E-Dec neurons, which synaptically inhibit other respiratory neurons involved in rhythm generation, thereby prolonging expiration (Feldman and Cohen, 1978; Richter et al., 1986, 1992; Ezure, 1990; Duffin et al., 1995).

\section{REFERENCES}

Averill DB, Cameron WE, Berger AJ (1984) Monosynaptic excitation of dorsal medullary respiratory neurons by slowly adapting pulmonary stretch receptors. J Neurophysiol 52:771-785.

Balis UJ, Morris KF, Koleski J, Lindsey BG (1994) Simulations of a ventrolateral medullary neural network for respiratory rhythmogenesis inferred from spike train cross-correlation. Biol Cybern 70:311-327.

Barillot JC, Bianchi AL (1971) Activité des motoneurones laryngés pendant les réflexes de Hering-Breuer. J Physiol (Paris) 63:783-792.

Berger AJ (1977) Dorsal respiratory group neurons in the medulla of cat: spinal projections, responses to lung inflation, and superior laryngeal nerve stimulation. Brain Res 135:231-254.

Berger AJ, Dick TE (1987) Connectivity of slowly adapting pulmonary stretch receptors with dorsal medullary respiratory neurons. J Neurophysiol 58:1259-1274.

Bianchi AL, Barillot JC (1975) Activity of medullary respiratory neurones during reflexes from the lungs in cats. Respir Physiol 25:335-352.

Bonham AC, McCrimmon DR (1990) Neurones in a discrete region of the nucleus tractus solitarius required for the Breuer-Hering reflex in rat. J Physiol (Lond) 427:261-280.

Bonham AC, Coles SK, McCrimmon DR (1993) Pulmonary stretch receptor afferents activate excitatory amino receptors in the nucleus tractus solitarii in rat. J Physiol (Lond) 464:725-745.

Davies RO, Kubin L, Pack AI (1987) Pulmonary stretch receptor relay neurones of the cat: localization and contralateral medullary projections. J Physiol (Lond) 383:571-585.

Duffin J, Ezure K, Lipski J (1995) Breathing rhythm generation: focus on the rostral ventrolateral medulla. News Physiol Sci 10:133-140. 
Ezure K (1990) Synaptic connections between medullary respiratory neurons and considerations on the genesis of respiratory rhythm. Prog Neurobiol 35:429-450.

Ezure K, Manabe M (1988) Decrementing expiratory neurons of the Bötzinger complex. II. Direct inhibitory synaptic linkage with ventral respiratory group neurons. Exp Brain Res 72:159-166.

Ezure K, Manabe M, Yamada H (1988) Distribution of medullary respiratory neurons in the rat. Brain Res 455:262-270.

Feldman JL (1986) Neurophysiology of breathing in mammals. In: Handbook of physiology, Sec 1, The nervous system, Vol 4, Intrinsic regulatory systems of the brain (Bloom FE, ed), pp 463-524. Bethesda, MD: American Physiology Society.

Feldman L, Cohen MI (1978) Relation between expiratory duration and rostral medullary expiratory neuronal discharge. Brain Res 141:172-178.

Feldman JL, Gautier H (1976) Interaction of pulmonary afferent and pneumotaxic center in control of respiratory pattern in cats. J Neurophysiol 39:31-44.

Feldman JL, Speck DF (1983) Interactions among inspiratory neurons in dorsal and ventral respiratory groups in cat medulla. J Neurophysiol 49:472-490.

Fukuda Y, Honda Y (1982) Roles of vagal afferents on discharge patterns and $\mathrm{CO}_{2}$ responsiveness of efferent superior laryngeal, hypoglossal, and phrenic activities in anesthetized rats. Jpn J Physiol 32:689-698.

Hayashi F, McCrimmon DR (1996) Respiratory motor responses to cranial nerve afferent stimulation in rats. Am J Physiol 271:R1054-R1062.

Hayashi F, Coles SK, Behnia R, McCrimmon DR (1991) Vagal input to the ventral respiratory group (VRG) of the rat. Soc Neurosci Abstr $17: 200$.

Jiang C, Lipski J (1990) Extensive monosynaptic inhibition of ventral respiratory group neurons by augmenting neurons in the Bötzinger complex in the cat. Exp Brain Res 81:639-648.

Kita H, Armstrong W (1991) A biotin-containing compound N-(2aminoethyl) biotinamide for intracellular labeling and neuronal tracing studies: comparison with biocytin. J Neurosci Methods 37:141-150.

Lindsey BG, Segers LS, Shannon R (1987) Functional associations among simultaneously monitored lateral medullary respiratory neurons in the cat. II. Evidence for inhibitory actions of expiratory neurons. J Neurophysiol 57:1101-1117.

Lipski J (1981) Antidromic activation of neurons as an analytical tool in the study of the central nervous system. J Neurosci Methods 4:1-31.

Manabe M, Ezure K (1988) Decrementing expiratory neurons of Bötzinger complex. I. Response to lung inflation and axonal projection. Exp Brain Res 72:150-158.
Ogilvie MD, Gottschalk A, Anders K, Richter DW, Pack AI (1992) A network model of respiratory rhythmogenesis. Am J Physiol 32:R962-R975.

Oku Y, Tanaka I, Ezure K (1992) Possible inspiratory off-switch neurones in the ventrolateral medulla of the cat. NeuroReport 3:933-936.

Pack AI (1981) Sensory inputs to the medulla. Annu Rev Physiol 43:73-90.

Parkes MJ, Lara-Muñoz JP, Izzo PN, Spyer KM (1994) Responses of ventral respiratory neurones in the rat to vagus stimulation and the functional division of expiration. J Physiol (Lond) 476:131-139.

Quintin L, Gillon JY, Saunier CF, Chouvet G, Chignone M (1989) Continuous volume infusion improves circulatory stability in anesthetized rats. J Neurosci Methods 30:77-83.

Remmers JE, Richter DW, Ballantyne D, Bainton CR, Klein JP (1986) Reflex prolongation of stage I of expiration. Pflügers Arch 407:190-198.

Richter DW (1982) Generation of maintenance of the respiratory rhythm. J Exp Biol 100:93-107.

Richter DW, Ballantyne D, Remmers JE (1986) How is the respiratory rhythm generated? A model. News Physiol Sci 1:109-112.

Richter DW, Ballanyi K, Schwarzacher S (1992) Mechanisms of respiratory rhythm generation. Curr Opin Neurobiol 2:788-793.

Rossignol S, Lund JP, Drew T (1988) The role of sensory inputs in regulating patterns of rhythmical movements in higher vertebrates. In: Neural control of rhythmic movements in vertebrates (Cohen $\mathrm{AH}$, Rossignol S, Grillner S, eds), pp 201-283. New York: Wiley.

Schwarzacher SW, Wilhelm Z, Anders K, Richter DW (1991) The medullary respiratory network in the rat. J Physiol (Lond) 435:631-644.

Segers LS, Shannon R, Saporta S, Lindsey BG (1987) Functional associations among simultaneously monitored lateral medullary respiratory neurons in the cat. I. Evidence for excitatory and inhibitory actions of inspiratory neurons. J Neurophysiol 57:1078-1100.

Smith JC, Ellenberger HH, Ballanyi K, Richter DW, Feldman JL (1991a) Pre-Bötzinger complex: a brainstem region that may generate respiratory rhythm in mammals. Science $254: 726-729$.

Smith JC, Greer JJ, Liu G, Feldman JL (1991b) Neural mechanisms generating respiratory pattern in mammalian brain stem-spinal cord in vitro. I. Spatiotemporal patterns of motor and medullary neuron activity. J Neurophysiol 64:1149-1167.

Zheng Y, Barillot JC, Bianchi AL (1991a) Patterns of membrane potentials and distributions of the medullary respiratory neurons in the decerebrate rat. Brain Res 546:261-270.

Zheng Y, Barillot JC, Bianchi AL (1991b) Are the post-inspiratory neurons in the decerebrate rat cranial motoneurons or interneurons? Brain Res 551:256-266. 